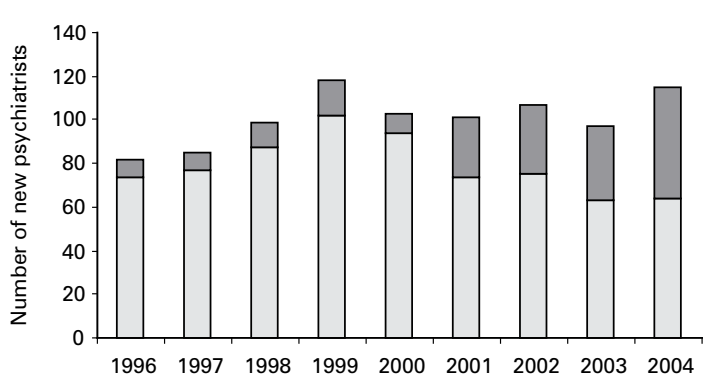

Figure 1. Total number of specialty licences in psychiatry distributed to doctors trained in Sweden or abroad, 1996-2004. Source: National Board of Health and Welfare, NPS database.

The number of psychiatrists employed in the public healthcare system care is forecast to rise to 2010. Thereafter the number will be stabilised at around I 500, and then fall again so that by 2020 it is expected to be at the same level as in 200 I (Figure 2).

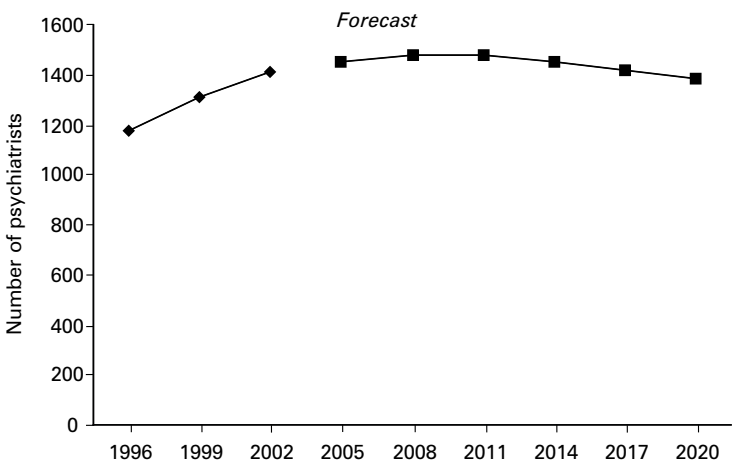

Figure 2. Total number of psychiatrists in the healthcare system, 1996-2002 and forecast for 2005-20. Source: National Board of Health and Welfare, NPS database.

According to a 2004 nationwide inquiry by the National Board of Health and Welfare directed at the county councils, there was some optimism regarding their ability to recruite new professionals, not only psychiatrists but also nurses and psychologists.
The recession of the 1990s, the subsequent changes in the labour market, job insecurity and persistent long-term unemployment are all part of the national context for increasing mental ill health.

\title{
Mental health in Finland
}

\section{Eero Lahtinen MD PhD}

Senior Medical Officer, Health Department, Health Promotion Group, Sjötullsgatan 8, Helsingfors, Finland, email eero.lahtinen@stm.fi

\begin{abstract}
he prevalence of mental illnesses in Finland generally reflects global trends, with a clear increase in the occurrence of depression and anxiety. At any time, between $4 \%$ and $9 \%$ of the population of 5.2 million suffer from major depressive disorders. Some $10-20 \%$ of the population experience depression during their lifetime. Bipolar depressive disorders affect $\mathrm{I}-2 \%$ and schizophrenia $0.5-1.5 \%$ of the population. The prevalence of alcoholism is $4-8 \%$.
\end{abstract}

The incidence of depression has increased over the past 15 years, in part reflecting better diagnostic practices and more widespread antidepressant treatment but also the altered living and psychosocial environment. Depression has been a growing cause of sickness absenteeism and work disability pensions - although the overall level of work disability has dropped.

Stress and burnout are common among employees, and are experienced in some form by over $50 \%$ of the workforce. The recession of the 1990s, the subsequent changes in the labour market, job insecurity and persistent long-term unemployment are all part of the national context for increasing mental ill health, although mental health trends parallel those of other countries. There is also concern about the growing extent of psychosocial problems among children and young people.

\section{Policy, programmes and preventive work}

Finland deployed the first comprehensive national suicide prevention programme between 1986 and 1996. There have since been several other national programmes to develop preventive and early intervention measures in mental health. They include the National Depression Programme, Mental Health in Primary Services, and the Meaningul Life, Early Interaction and the Effective Family programmes.

A mental health policy was initially formulated in 1993. It focused on advocacy, promotion, prevention, treatment and rehabilitation. Part of the mental health policy has been the de-institutionalisation of psychiatric care. A substance misuse policy was initially formulated in 1997.

The Ministry of Social Affairs and Health produced quality guidelines for mental health services in 2001 and is working on quality guidelines for supportive housing for people with mental health problems. The government has also adopted a Drug Policy Action Programme for 2004-07. The national Alcohol Programme was launched in 2004. Comprehensive quality guidelines for health promotion at the local level are in preparation, linked with the updating of the Primary Healthcare Act. 
National strategies such as the Health 2015 public health programme and the government's Goal and Action Plan for Social Welfare and Healthcare 2004-07 stress mental health and mental health promotion. Both policy strategies also highlight the need to improve mental health among young people and children.

Ongoing programmes (e.g. in occupational health) to encourage people to extend their working lives emphasise better intervention to safeguard mental health.

Two interlinked national projects, the National Healthcare Project and the National Development Project for Social Services, make mental health and the improvement of mental health services integral to the development of the health and welfare systems.

Prevention to forestall mental ill health is crucial to programmes to develop child welfare. Efforts are under way to boost cooperation between schools, day care centres and healthcare services for the prevention of mental health problems among children and young people, and for identifying problems and providing help at an early stage.

\section{Mental health services}

The healthcare system in Finland is decentralised. It is organised at local level within the country's 432 municipalities spread over five provinces. Some municipalities contain very small and scattered populations. The country has 21 hospital districts and specialised healthcare is provided at this level.

Municipalities are responsible for organising outpatient mental healthcare and rehabilitation through the primary healthcare system provided at health centres and through social services. Specialised mental healthcare comprises in-patient services arranged through hospital districts, as well as out-patient services provided by hospital districts and health centres.

As municipalities have taken a greater share of the responsibility for arranging health services, the role of primary healthcare in organising mental health services has increased.

Since the early 1990s there has been a major shift away from institutional in-patient care for psychiatric patients towards out-patient community care. In 1980, there were 4.2 beds for psychiatric patients per 1000 inhabitants. By 1994, the ratio was 1.3 per 1000 inhabitants. Correspondingly, out-patient visits rose from 520000 in 1980 to 1290000 in 1997.

A challenge for mental healthcare is to reduce regional disparities in quality and availability of services and ensure comprehensive mental health planning at local level. Programmes seek to develop supportive out-patient services for long-term patients, with more supported housing, day centres, support staff and guided leisure activities, and improved support for carers.

\section{Rehabilitation}

Occupational healthcare focuses on vocational rehabilitation in addition to preventive work. The Social
Insurance Institution and labour authorities have responsibility for organising vocational rehabilitation. The Ministry of Social Affairs and Health has focused on the need for increased support for rehabilitation services. An active approach to rehabilitation in general, and that relating to mental health problems in particular, is a characteristic of Finnish health policy.

The report of an expert group appointed by the Ministry of Social Affairs and Health (Lehto et al, 2005) highlighted various needs in the area of rehabilitation that are being addressed in current work. They include:

o the crucial role of psychotherapy and the need to link it to other activities promoting functional capacity and social interaction

o an emphasis on rehabilitation services, and especially vocational rehabilitation, for example by increasing the training and skills of rehabilitation professionals

o cooperation between occupational health services, workplaces and rehabilitation providers.

\section{Organisations}

In addition to local authorities, numerous nongovernmental organisations play a central role in providing mental health services and rehabilitation. The largest include:

the Finnish Association for Mental Health

the Finnish Central Association for Mental Health

O the VATES Foundation (which promotes the employment of people with disabilities)

o the Rehabilitation Foundation.

The main state authorities and related agencies dealing with mental health are:

O the Ministry of Social Affairs and Health

O the National Research and Development Centre for Welfare and Health (STAKES)

o the Finnish Institute for Occupational Health

$O$ the Ministry of Labour.

Mental health also features in the activities of other branches of government, including the Ministry of Education, Ministry of Defence and the development programmes of the Ministry for Foreign Affairs.

\section{Changing profile}

Psychiatric care in Finland has been transformed over the last quarter of a century, from a system focused on in-patient institutional care and treatment, when Finland had one of the highest ratios of hospital beds to population in Europe, to one essentially based on community services. Finland's deep economic recession in the 1990s (the most dramatic ever seen in an industrialised country) disrupted the smooth transition to community-based care. Resources were cut and the tight financial situation of the municipalities meant that greater priority was given to somatic, general health services.

Now, additional allocations to mental health services have been granted by the government to
Since the early 1990s there has

been a major shift away from institutional in-patient care for psychiatric patients towards out-patient community care. In 1980, there were 4.2 beds for psychiatric patients per 1000 inhabitants. By 1994, the ratio was 1.3 per 1000 inhabitants.

The healthcare system in Finland is decentralised. It is organised at local level within the country's 432 municipalities spread over five provinces. Some municipalities contain very small and scattered populations. The country has 21 hospital districts and specialised

healthcare is provided at this level. 
support the development of the sector, for example in the context of the National Healthcare Project and the National Development Project for Social Services.

Despite the autonomy of municipalities in arranging services, a large number of municipalities have adopted central government recommendations on mental health and interventions promoting mental health for children. Efforts are under way to tackle regional disparities in service availability.
At the same time, population ageing and the need to encourage a longer working life have raised the profile of good mental health as integral to people's capacity to lead active and rewarding lives.

\section{Reference}

Lehto, M., Lindström, K., Lönnqvist, J., et al (2005) Mielenterveyden häiriöt työkyvyttömyyseläkkeen syynä - ajatuksia ehkäisystä, hoidosta ja kuntoutuksesta. [Mental disorders as a cause of disability pensions - ideas about prevention, treatment and rehabilitation.] Helsinki: Ministry of Health.

\section{French psychiatry}

\section{Michel Botbol MD}

\begin{abstract}
Until very recently
France was

ranked second

in the world in

terms of the per

capita provision

of psychiatrists

(nearly four times

higher than

that in the UK,

for example), with, at its peak,

about 13500

rench psychiatry is currently facing a period of profound change, as many of what were considered its most specific characteristics and traditions have been called into question. It is therefore difficult to draw a profile of French psychiatry, because it has to take into account a radical splitting between, on the one hand, what is still the common profile of most French psychiatrists and, on the other, the new model imposed by stakeholders and policy makers who want French psychiatry to take on a more Anglo-Saxon profile, with evidencebased practice coming to the fore, for instance.
\end{abstract}

psychiatrists for a general population of some 60

million.... There

is also a marked

geographical

disparity: the

population density

of psychiatrists is

10 times higher in

Paris than in the

north-east of the

country.

Psychiatrist, World Psychiatric Association Zonal Representative for Western Europe (Zone 6);

Chair of the Therapeutic Section of the Child and Adolescent College of the French Federation of Psychiatry, 116 Rue du Moulin des Pres, 75013 Paris, France, email mbotbol@wanadoo.fr

\section{Staffing}

In this context workforce issues are becoming a major concern for French psychiatrists. Until very recently France was ranked second in the world in terms of the per capita provision of psychiatrists (nearly four times higher than that in the UK, for example), with, at its peak, about 13500 psychiatrists for a general population of some 60 million. Nevertheless, around $20 \%$ of public hospital positions remain vacant, which reflects a growing preference for private practice. There is also a marked geographical disparity: the population density of psychiatrists is 10 times higher in Paris than in the north-east of the country.

Most stakeholders wish to correct the French figure for psychiatrist density. There is a trend to reduce the number of all types of doctor to the European average, but psychiatry is particularly affected in this regard, and since 1990 the number of psychiatry students has dropped by $37 \%$. Accordingly, the number of psychiatrists will be $40 \%$ lower in 2020 . If there is no significant increase in the number of psychiatric students, or if psychiatrists' freedom to choose their type of practice is maintained, the present disparity in the provision of psychiatric resources will be exacerbated, and a large part of the French population will have very limited access to psychiatric services.
The same disparity also exists for allied professions: France has 58000 nurses working in psychiatry. Their number is set to decrease with the recent termination of a specific psychiatric nursing diploma. There are also 35000 psychologists and psychoanalysts, but for historical reasons they are still not officially considered health professionals (the idea was opposed by both medical and psychological organisations for ideological or economic reasons). The psychologist's role in both the public health sector and private practice is limited, because it is not recognised by the national social security system.

\section{Education}

In France, psychiatric specialisation follows a 4-year national diploma programme, which is open to students who have passed the 6-year general medicine programme. Access to medical schools is very tightly regulated. These training programmes are offered by at least one public university in each of the country's 12 regions. At the end of the programme for general medicine the number of positions available for each specialty is decided nationally; for psychiatry (including child and adolescent psychiatry) this number has been recently increased slightly, to 200. Medical students choose their specialisation in accordance with their rank in a national competitive examination at the end of the programme for general medicine.

The specialisation programme includes 4 years of residency training in psychiatric wards with at least I year in child psychiatry for future general psychiatrists and I year of general psychiatry for future child psychiatrists. Each student has to take a number of 'education units'; most are optional and particular to each university, but some are compulsory, including diagnosis and treatment using different techniques and theories. At most universities this allows prominence to be given to psychotherapeutic techniques and theory, especially psychodynamics and 